\title{
New Research Avenues on Multimedia based learning in the $\mathrm{EU}$
}

\author{
L. Rodríguez-Roselló \\ European Commission \\ Directorate General XIII- Head of Division \\ Telematics Applications and Sevices for Education and \\ Training and Research Networks
}

\author{
Keywords \\ World-Wide market, European Action, Education Policy, R\&D strategies
}

The growth of knowledge creation underpinning explosive technological development will increase further in the foreseeable future, and the integration of our economies will continue to entail increased specialisation. This will mean a significant shift in economic activities and therefore of the skills needed to support these activities. The pace and the significance of this technological change is such that industry cannot rely only on new entrants to the job market to match the need for new skills, as was the case in the past. In fact students and the teachers themselves feel uneasy, they are aware of the gap between their training and the needs of society, and want training better suited to their needs.

These macro-economic factors generate a growing and highly diversified demand that the current educational and training system cannot cope with. In addition, there is no prospect of a substantial increase in financial resources, however, the development of new approaches to learning, building on an extensive use of educational technology opens new perpectives to meeting the above challenge. Research and development is therefore needed to prepare for effective, efficient deployment of ICT for learning.

The breadth of research needed cannot be undertaken by small communities of researchers in the Member States working at the point of intersection between education and computer science. A critical mass of research capacity can only be found at the European Union level. It is not enough to bring researchers together, progress will also result from the joint efforts of curriculum developers and the wide range of stakeholders in the education and training system working with the researchers. In addition, thanks to the completion of the internal market and the deregulation of the telecommunications industry, more and more actors are operating at the EU level and are preparing themselves for the world-wide competition. 
operating at the EU level and are preparing themselves for the world-wide competition.

Nowadays there is a broadly shared vision that the success of the information society in the EU is critically dependent on effective delivery of life-long learning to all its citizens and that a large scale European wide action is needed to bring together the expertise available within the Member States. Nowadays, competition is no longer limited to goods, it also includes services that can be delivered at a distance such as education and training. It is of paramount importance that the EU is ready to compete on this key market.

It is also found that one of the main challenges of the planned action is to reduce the time needed to apply research findings at all level of the education and training institution as well as within companies. Research should therefore focus on demonstrating measurable, long lasting gains at affordable costs. This means that technical R\&D should be supplemented with relevant, focussed socio-economic research which will help understanding how institutions can best adapt to society's needs and offer new and effective models for learning, how companies will organize training and last, but not least, how the social fabric will integrate those radical changes.

A seamless deployment of the technologies for knowledge and skills acquisition in the information society will result from the convergence of efforts and interest of the different actors: the multimedia industry, the network and telecommunication providers, the users at schools, home, universities and other educational institutions, at companies, as well as on national policies in the member states. Several programmes of the European Commission may stimulate this deployment.

The role of the RTD\&D programme in this field is to provide the EU with blueprints for this implementation

This goal can be achieved by testing and showing how innovative systems, methods, and services, if designed for efficiency, scalability and accessibility, can apply downstream the results of basic research to cover the users needs. It should cater then for:

\section{Efficiency}

Research is needed to significantly improve the learning process in order to achieve significant lasting and measurable learning gains at a known cost. R\&D should address the core of the education process and not just technological addons.

\section{Scalability}

All important factors, technical, social, or organisational that could impact larger scale, progressive deployment should be investigated and understood. 


\section{Accessibility}

The solutions selected should allow for a progressive, no disruptive, affordable implementation across the EU catering for a wide diversity of users.

The trends in the education institutions and in companies, the trend in education and training policies and the difficulties encountered in attempts to deploy educational technologies at a reasonable large scale have been analysed in depth and many experimental results are known from previous research and other actions. The Educational Multimedia Task Force report provided a substantial contribution: it identified the needs for the specialisation of universities and the need for networking, enabling cooperation and providing new virtual learning spaces; new industrial training based on on-the-job access meeting the needs of the learning organisation, the move towards a more learner centred approach at the educational system.

A system approach to education and training is needed based on state of the art learning sciences and cognitive science research. An effective action cannot be reduced to pure technical $R \& D$, the efforts should be balanced between the development of tools and methods to support new learning models, advanced content development and their validation in a real life context.

R\&D should be based mainly, but not only, on affordable technologies, in other words, based on an intercept strategy with emerging cost-effective technologies and services.

On the basis of the previous achievements of the Telematics Applications Programme and the Task Force on Educational Multimedia, the actions are to tackle all the issues required for the improvement of learning, the learning processes, the content and services and the access infrastructure.

For the improvement of the learning process, sustainable learning gains will be achieved by better supporting more autonomous and more individualised learning, addressing all the components of a modular instructional management system (local learner support, peer learning, remote tutoring, course/curriculum design systems, accreditation systems, knowledge assets management and easy access to learning resources together with new delivery models).

For the development of higher quality learning material three different perspectives are to be considered: the content itself; the embedded pedagogical or didactic approaches; and the adaptability to the learner needs. That means research on new instructional design tools, learner modelling techniques, knowledge modelling and learning ergonomics. The material will range from simple distributed hypermedia to advanced simulation environments such as virtual laboratories.

Providing access to learning resources and services to all learners (e.g. in institutions, on-the-job or at home, including those in remote areas, nomadic or disabled persons) is a key requirement. The development of common platforms will allow full access to services across heterogeneous networks, addressing harmonised identification and retrieval of learning and of other knowledge resources. 
All the above will lead to seamless advanced learning services which will harness the technologies in order to be more efficient and accessible to all learners regardless of their location, language and catering for a broad diversity of needs.

The implementation could follow the following lines:

- Establish the scientific base

- RTD on components of learner centred learning systems

- Validate research results in experimental studies

The action should also allow for proposals containing innovative, high risk but also high pay-off ideas that may advance knowledge on the main themes such as proposals that cut-across traditional disciplines. Finally, the action should contribute to the standardisation process by launching pre-standardisation activities aimed at ensuring the reusability of multimedia material and the interoperability at the tools and at the service level.

\section{BIOGRAPHY}

Luis Rodríguez-Roselló received his Telecommunications Engineer degree from the Technical University of Madrid. He has worked as Director of the Research and Development Department for the ITE (Instituto de Tecnologías para la Educacion) depending of the Spanish Education Ministry and later as Main Advisor for the New Technologies Program of the same Ministry. Since 1989, he is Head of Division within the European Commission, DG-XIII, and also coordinates the Educational and Multimedia Software Task Force. 